\title{
Phosphorescence quantum yield enhanced by intermolecular hydrogen bonds in Cu4l4 clusters in the solid state
}

Article

Accepted Version

Mazzeo, P. P., Maini, L., Petrolati, A., Fattori, V., Shankland, K. and Braga, D. (2014) Phosphorescence quantum yield enhanced by intermolecular hydrogen bonds in Cu4l4 clusters in the solid state. Dalton Transactions, 43 (25). pp. 9448-9455. ISSN 1364-5447 doi: https://doi.org/10.1039/c4dt00218k Available at https://centaur.reading.ac.uk/39207/

It is advisable to refer to the publisher's version if you intend to cite from the work. See Guidance on citing.

To link to this article DOI: http://dx.doi.org/10.1039/c4dt00218k

Publisher: Royal Society of Chemistry

All outputs in CentAUR are protected by Intellectual Property Rights law, including copyright law. Copyright and IPR is retained by the creators or other copyright holders. Terms and conditions for use of this material are defined in the End User Agreement.

www.reading.ac.uk/centaur 
Central Archive at the University of Reading

Reading's research outputs online 


\title{
Phosphorescence quantum yield enhanced by intermolecular hydrogen bonds in $\mathrm{Cu}_{4} \mathrm{I}_{4}$ clusters in the solid state $\dagger$
}

\author{
Paolo P. Mazzeo, a Lucia Maini, ${ }^{{ }^{a}}$ Alex Petrolati, a Valeria Fattori, ${ }^{\star} b$ \\ Kenneth Shankland ${ }^{c}$ and Dario Bragaa
}

\begin{abstract}
Organo-copper(I) halide complexes with a $\mathrm{Cu}_{4} \mathrm{I}_{4}$ cubane core and cyclic amines as ligands have been synthesized and their crystal structures have been defined. Their solid state photophysical properties have been measured and correlated with the crystal structure and packing. A unique and remarkably high luminescence quantum yield (76\%) has been measured for one of the complexes having the cubane clusters arranged in a columnar structure and held together by $\mathrm{N}-\mathrm{H} \cdots$ l hydrogen bonds. This high luminescence quantum yield is correlated with a slow radiationless deactivation rate of the excited state and suggests a rather strong enhancement of the cubane core rigidity bestowed by the hydrogen bond pattern. Some preliminary thin film deposition experiments show that these compounds could be considered to be good candidates for applications in electroluminescent devices because of their bright luminescence, low cost and relatively easy synthesis processes.
\end{abstract}

Copper(I) halide complexes constitute a large family of compounds based on a relatively abundant metal element and are of photochemical and photophysical interest. ${ }_{-}^{11}$ Depending on their versatile coordination environment these compounds play a unique role in both physical and biological research and application. ${ }^{3}$ Recently there has been a surge of interest in studying these complexes, which are currently at the forefront of coordination chemistry and crystal engineering research ${ }^{12}{ }_{-}^{15}$ as active materials for optoelectronic devices. ${ }^{16_{-}-19}$

In the past few decades, new concepts for lighting and display applications have been the focus of extensive research. ${ }^{20}{ }_{-}^{22}$ Organic Light-Emitting Diodes (OLEDs) are the most promising devices for these tasks, as they can be manu- factured with low cost processes and can be purpose-built in thin, flexible and lightweight substrates. ${ }^{23}$ Organometallic complexes based on iridium, ${ }^{24}$ platinum ${ }^{25}$ and osmium ${ }^{26}$ are commonly used as materials in OLEDs due to their high emission quantum yield and wavelength tunability, while very

\footnotetext{
a'Dipartimento di Chimica "G.Ciamician", Università di Bologna, Via Selmi 2, 40126 Bologna, Italy. E-mail: 1.maini@unibo.it

${ }^{\mathrm{b}}$ Istituto per la Sintesi Organica e la Fotoreattività (ISOF) - CNR, Via Gobetti 101 40129 Bologna, Italy. E-mail: valeria.fattori@isof.cnr.it

'School of Pharmacy, University of Reading, Whiteknights, Reading RG6 6AD, UK

$\dagger$ Electronic supplementary information (ESI) available. CCDC 975300,

989490-989492. For ESI and crystallographic data in CIF or other electronic

format see DOI: $10.1039 / \mathrm{c} 4 \mathrm{dt} 00218 \mathrm{k}$
}

recently, copper(I) has appeared in the literature as a good candidate to replace such expensive metals for OLEDs. ${ }^{16,19,27}$

Whilst the luminescence in solution in halogen-organocopper(I) complexes has been studied for decades, ${ }^{6,8}$ very little work has been done on these complexes in the solid state. ${ }^{19,27}{ }_{-}^{29}$ However, the photophysical properties of the solids could be very diferent from those in solution due to the molecular organization through the crystals, which can be expected to afect the energies and/or the kinetics of the excited states..$_{-}^{32}$ In this respect, polymorphism (i.e. the existence of diferent crystal forms for the same molecular or supramolecular entity) could play a key role in determining the final photophysical properties. ${ }^{32}$

Ford et al. extensively studied the luminescence properties of copper(I) halogen complexes having a $\mathrm{Cu}_{4} \mathrm{X}_{4}$ core with a cubane-like geometry, ${ }^{6,33}{ }_{-}{ }^{36}$ and showed that the luminescence behaviour and the environment (solvent or rigid matrix) of the complexes are strictly related. ${ }^{33}$

In the case of the cluster $\mathrm{Cu}_{4} \mathrm{I}_{4}$ ( pyridine $)_{4},{ }^{4}$ for example (hereafter 1), two distinct emission bands were observed in solution, whose high-energy band was attributed to a triplet halide-to-ligand charge transfer ( ${ }^{X L C T}$ ), while the low-energy

emission band was attributed to a triplet $\mathrm{Cu}$-I cluster-centred $\left({ }^{3} \mathrm{CC}\right)$ excited state with the excitation localized to the $\mathrm{Cu}_{4} \mathrm{I}_{4}$ core, only possible in the presence of an interaction between the metal centres. ${ }^{37}$

The ${ }^{3} \mathrm{CC}$ emission band was shown to display a peculiar sensitivity to the temperature and rigidity of the medium. ${ }^{38}$ 

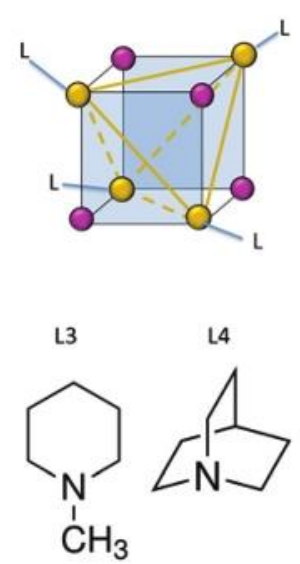

L1<smiles>c1ccncc1</smiles>

L2<smiles>C1CCNCC1</smiles>

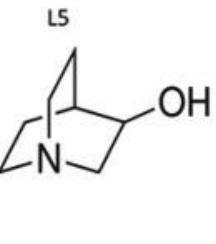

Scheme 1 General representation of a $\mathrm{Cu}_{4} \mathrm{I}_{4} \mathrm{~L}_{4}$ cubane cluster (yellow = copper; purple = iodine); $\mathrm{L} 1$ = pyridine, $\mathrm{L} 2=$ piperidine, $\mathrm{L} 3=$

$\mathrm{N}$-methylpiperidine, L4 = quinuclidine, L5 = 3-quinuclidinol.

In this paper we aim to gain insight into the correlation between the photophysics and structure of $\mathrm{Cu}_{4} \mathrm{I}_{4} \mathrm{~L}_{4}$ cubane complexes in which every copper ion binds to three iodide atoms and then completes its first coordination sphere with a $\mathrm{N}$ based ligand such as pyridine (L1), piperidine (L2), N-methylpiperidine (L3), quinuclidine (L4), or 3-quinuclidinol (L5) (see Scheme 1).

Apart from pyridine, we considered only saturated ligands with the aim of excluding the photophysical process involving the ligand's $\pi$ system and determining which parameters afect the cluster-centred characteristics such as basicity, ability to form hydrogen bonds, and diferent groups bonded to the coordinating nitrogen. The diferent $\mathrm{pK}_{\mathrm{b}}$ values allow to determine whether the emission quantum yield in the solid state is related to the bond strength between ligands and copper atoms.

The substitution of hydrogen with a methyl group on the coordinating nitrogen atom will allow us to determine whether the $\mathrm{CC}$ excited state radiationless deactivation due to the $\mathrm{N}-\mathrm{H}$ bending modes coupling, as hypothesized in solution, ${ }^{33}$ can be removed.

Moreover, the ligands show a progressive rigidity and a diferent ability to form H-bonds and consequently allow to investigate how the vibrations involving the ligand $\sigma$ backbone can influence the photophysical properties of the complexes. Some preliminary thin film deposition experiments have been carried out in order to predict the applications of these com- plexes in solid-state optoelectronic devices.

\section{Results and discussion}

Six tetrakis $\left(\left(\mu_{3}\right.\right.$-Iodo)-ligand-copper(I) $)$ cubane complexes have been synthesized: $\mathrm{Cu}_{4} \mathrm{I}_{4}$ pyridine ${ }_{4}(1), \mathrm{Cu}_{4} \mathrm{I}_{4}$ piperidine ${ }_{4}(2), \mathrm{Cu}_{4} \mathrm{I}_{4} \mathrm{~N}$ methylpiperidine ${ }_{4}(3), \mathrm{Cu}_{4} \mathrm{I}_{4}$ quinuclidine ${ }_{4}(4)$ and two crystal forms of $\mathrm{Cu}_{4} \mathrm{I}_{4}$ (3-quinuclidinol) $)_{4}$ (5a and $5 \mathrm{~b}$ ).
For all complexes, the crystal structure and photophysical properties in the solid state have been measured. Complexes 1 and 2 have already been studied and their crystal structure and photophysical data (apart from solid state emission quantum yields) have been reported, 4,33,38,39 while 3, 4, 5a and 5b are accounted here for the first time.

\section{Synthesis and crystal structures}

Compounds 1 and 2 were obtained as crystalline powders by following the previously reported synthesis, while 3, 4, 5a and $5 b$ were obtained by modification of the previously reported synthesis. Single crystals of 3,4 , and $5 b$ were obtained by triple layer crystallization (see the Experimental part). While no single crystal suitable for SCXR analysis of 5 a could be obtained, its structure has been determined from X-ray powder difraction data via Rietveld refinement of a starting model derived from the single-crystal coordinates of 4 as we found that the two structures are isomorphous (see below).

The crystal structures of 1-5 are characterized by the presence of distorted cubane clusters (see Fig. 1) and in all compounds the $\mathrm{Cu}-\mathrm{Cu}$ distances are compatible with metallophilic interactions as, inside the $\mathrm{Cu}_{4} \mathrm{I}_{4}$ clusters, they are shorter than two times the van der Waals radius of $\mathrm{Cu}$ which has been recently evaluated as $1.92 \AA^{40,41}$ (see Table 1). The ligand molecules are located on the vertex of the tetrahedral coordinating copper atoms as a sort of blades.

In compounds 1, 2 and 3 the complexes are piled up to form columns which run parallel to one another (see Fig. 2). In compound 1 only weak $\mathrm{C}-\mathrm{H} \cdots \pi$ interactions are present among the discrete entities, while compound 2 is characterized by the presence of intermolecular hydrogen bonds. The hydrogen atoms belonging to the nitrogen point to the iodine atoms of an adjacent cluster and form $\mathrm{N}-\mathrm{H} \cdots \mathrm{I}$ interactions. Evidence of the hydrogen bond comes from the alignment of the N-H-I atoms $\left(159^{\circ}(1)\right)$ and the H-I distance $(2.935(3) \AA)$ which is shorter than the sum of the atomic radii $(3.16 \AA) .{ }^{42}$ Since the clusters are piled up, each cubane cluster is pinched by eight hydrogen bonds, four on one side and four on the opposite side (see Fig. 2b).

In compound 3 the $\mathrm{Cu}-\mathrm{Cu}$ distances are about 2.868(3) $\AA$ and 2.946(2) $\AA$, slightly longer than the other compounds, but

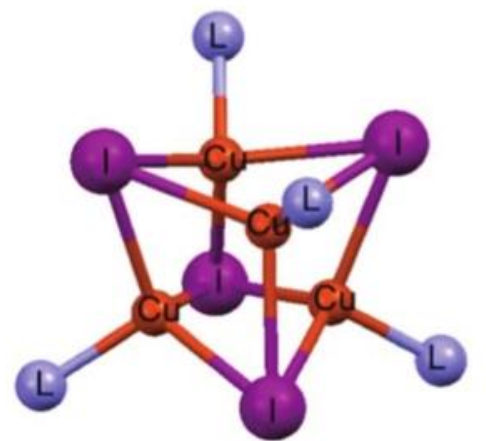

Fig. 1 Distorted cubane cluster with nitrogen atoms belonging to the ligand coordinating the copper atoms. 
Table 1 Interatomic distances in $\mathrm{Cu}_{4} \mathrm{l}_{4}$ clusters

\begin{tabular}{|c|c|c|c|c|}
\hline & $\mathrm{Cu}-\mathrm{Cu}(\AA)$ & $\mathrm{Cu}-\mathrm{I}(\AA)$ & & $\mathrm{I}-\mathrm{I}(\AA)$ \\
\hline \multirow[t]{6}{*}{1} & $2.619(2)$ & $2.630(4)$ & $2.697(4)$ & $4.443(7)$ \\
\hline & $2.684(6)$ & $2.665(3)$ & $2.701(4)$ & $4.478(8)$ \\
\hline & $2.689(3)$ & $2.669(6)$ & $2.720(7)$ & $4.488(2)$ \\
\hline & $2.707(8)$ & $2.670(3)$ & $2.733(2)$ & $4.513(2)$ \\
\hline & $2.719(4)$ & $2.677(5)$ & $2.790(2)$ & $4.529(4)$ \\
\hline & $2.721(1)$ & $2.692(3)$ & $2.794(4)$ & $4.594(2)$ \\
\hline \multirow[t]{3}{*}{2} & $2.595(5)$ & \multicolumn{2}{|c|}{$2.682(3)$} & $4.473(3)$ \\
\hline & $2.640(1)$ & \multicolumn{2}{|c|}{$2.687(3)$} & $4.584(1)$ \\
\hline & & \multicolumn{2}{|c|}{ 2.711(4) } & \\
\hline \multirow[t]{3}{*}{3} & $2.868(3)$ & \multicolumn{2}{|c|}{$2.690(1)$} & $4.351(1)$ \\
\hline & $2.946(2)$ & \multicolumn{2}{|c|}{$2.696(4)$} & $4.480(2)$ \\
\hline & & \multicolumn{2}{|c|}{$2.683(2)$} & \\
\hline \multirow[t]{4}{*}{4} & $2.671(2)^{\mathrm{a}}$ & \multicolumn{2}{|c|}{$2.669(2)^{\mathrm{a}}$} & $4.459(2)^{\mathrm{a}}$ \\
\hline & $2.696(3)^{\mathrm{a}}$ & \multicolumn{2}{|c|}{$2.685(8)^{\mathrm{a}}$} & $4.493(1)^{\mathrm{a}}$ \\
\hline & $2.725(3)^{\mathrm{b}}$ & \multirow{2}{*}{\multicolumn{2}{|c|}{$\begin{array}{l}2.695(1)^{\mathrm{a}} \\
2.682(2)^{\mathrm{b}}\end{array}$}} & $4.456(1)^{\mathrm{b}}$ \\
\hline & & & & \\
\hline \multirow[t]{4}{*}{$5 a$} & $2.695(2)^{\mathrm{a}}$ & \multicolumn{2}{|c|}{$2.692(2)^{\mathrm{a}}$} & $4.498(1)^{\mathrm{a}}$ \\
\hline & $2.720(2)^{\mathrm{a}}$ & \multicolumn{2}{|c|}{$2.709(3)^{\mathrm{a}}$} & $4.533(2)^{\mathrm{a}}$ \\
\hline & $2.749(3)^{\mathrm{b}}$ & \multicolumn{2}{|c|}{$2.719(5)^{\mathrm{a}}$} & $4.496(3)^{\mathrm{b}}$ \\
\hline & \multicolumn{4}{|c|}{$2.706(7)^{b}$} \\
\hline \multirow[t]{6}{*}{$5 b$} & $2.648(3)$ & $2.661(3)$ & $2.696(4)$ & 4.42972) \\
\hline & $2.660(2)$ & $2.679(6)$ & 2.699(6) & $4.438(3)$ \\
\hline & $2.662(4)$ & 2.683(3) & 2.704(3) & $4.441(3)$ \\
\hline & $2.705(4)$ & $2.688(8)$ & $2.715(2)$ & $4.588(4)$ \\
\hline & $2.706(2)$ & $2.689(7)$ & $2.717(4)$ & $4.504(2)$ \\
\hline & $2.745(1)$ & $2.692(2)$ & $2.721(1)$ & $4.564(2)$ \\
\hline
\end{tabular}

${ }_{\mathrm{a},}^{\mathrm{b}}$ Referred to crystallographic independent cubane clusters in the structure.
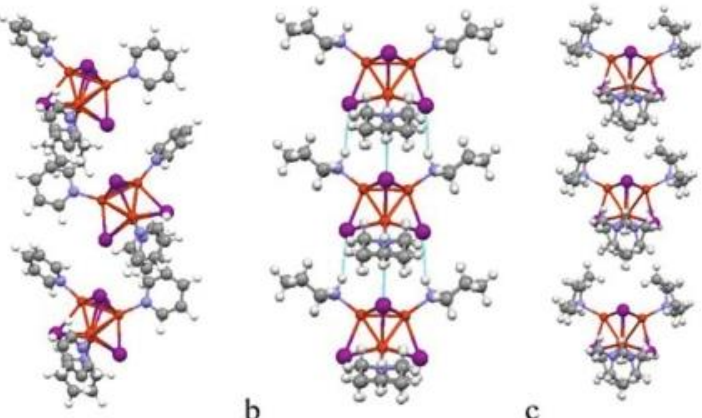

a

b

c
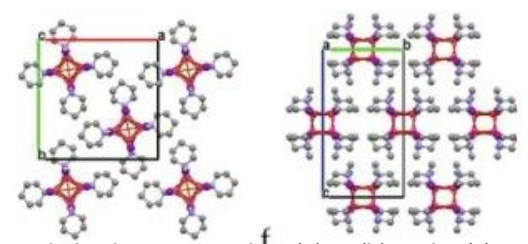

Fig. 2 The columns of cubahe moieties in compounds 1 (a), 2 (b) and 3 (c) and how they pack in the crystal structures 1 (d), 2 (e) and 3 (f). In

2 (b) the $\mathrm{N}-\mathrm{H} \cdots$. I hydrogen bonds are highlighted in blue. In $\mathrm{d}, \mathrm{e}, \mathrm{f}$, hydrogen atoms are omitted for the sake of clarity.

it seems not to afect the photophysical properties. As for 2 , in compound 3 the cubane clusters are piled up in columns, but the tertiary nitrogen atom of the $\mathrm{N}$-methylpiperidine rules out the formation of hydrogen bond interactions among the cubane complexes.

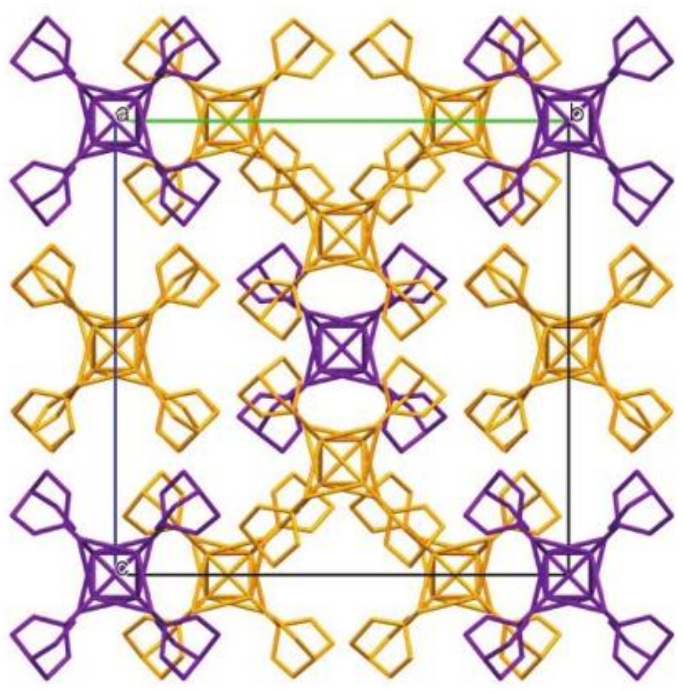

Fig. 3 Crystal structure of 4 . The two independent cubane moieties are coloured in purple and orange. Hydrogen atoms are omitted.

Compound 4 crystallizes with a cubic lattice and is characterized by two diferent cubane moieties that are not symmetry related. In the structure, one asymmetric cluster occupies the node and the centre of the cell while the second asymmetric cluster is located on the face. This particular arrangement pre- vents the formation of columns observed in the previous struc- tures (Fig. 3).

Two crystal forms $5 a$ and $5 b$ have been obtained by reacting $\mathrm{CuI}$ with quinuclidinol. Single crystals of 5 a could not be obtained, but its powder X-ray difraction pattern shows it to be isomorphous with structure 4 (Fig. 4). The unit cell para- meter of 5 a was easily refined using the cell parameter of 4 as the starting point.

The structure of $5 a$ was then solved from the powder data using, as the initial coordinates for rigid-body Rietveld refinement, the structure of the compound 4 conveniently modified

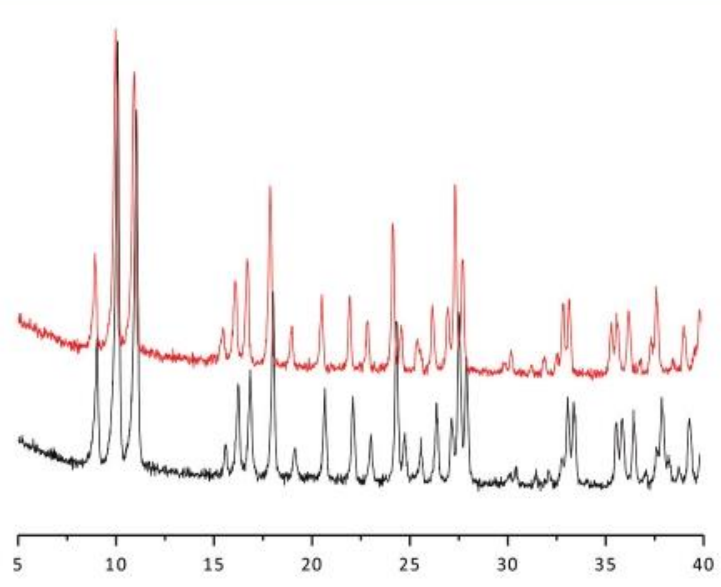

Fig. $4 \mathrm{X}$-ray powder pattern of $5 \mathrm{a}\left(\mathrm{r}^{2} \mathrm{\theta}\right.$ (line $)$ compared with that of the isomorphic compound 4 (black line). 
by changing the $\mathrm{H}$ atoms into $\mathrm{O}-\mathrm{H}$ groups in positions 3,5 and 8 with respect to $\mathrm{N}$ in the quinuclidinol ligand with $1 / 6$ occupancy (because of the rotation along $\mathrm{C}_{3}$ and of the chirality of the ligand in those positions).

The position of the hydroxyl groups is disordered and although the hydroxyl groups belonging to diferent clusters could form hydrogen bonds, a hydrogen bond pattern cannot be identified.

Compound $5 \mathrm{~b}$ presents the same complex units as $5 \mathrm{a}$ and, in this case, the hydroxyl groups are disordered mainly over two positions. The $\mathrm{Cu}_{4} \mathrm{I}_{4} \mathrm{~L}_{4}$ can be described as triangular based pyramids, which are arranged in layers with the parallel bases to form a flat side while the opposite side is character-ized by the presence of the vertex of the pyramids. The layers face one another in a complementary way and form curvy monodimensional channels in which disordered solvent mole- cules are trapped (see Fig. 5). The presence of solvent mole- cules in the crystal structure has been confirmed by TGA

analysis (see ESI $\dagger$ ).

\section{Conversions}

A variable temperature XRPD analysis has been performed on $5 \mathrm{~b}$ with in situ characterization of the powder. As shown in Fig. 6 , on heating up the powder to $100{ }^{\circ} \mathrm{C}$, loss of crystallinity

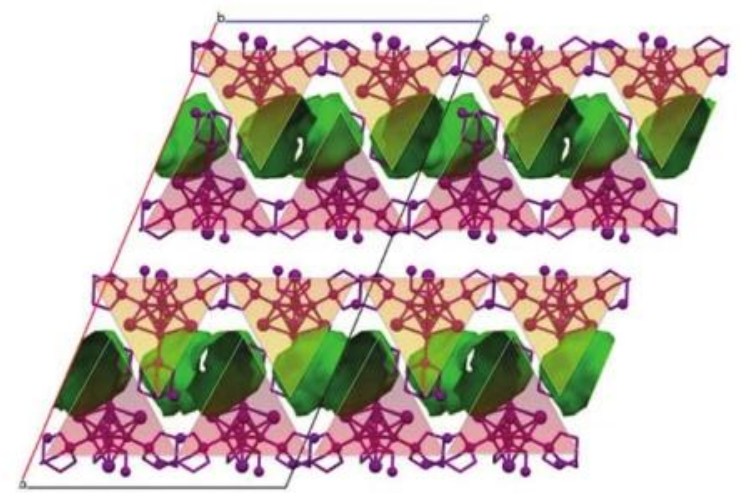

Fig. 5 Voids analysis in compound 5 b. Hydrogen atoms are removed for clarity. Curvy monodimensional channels $(\varnothing 8.57 \AA$ ) are present in the structure along the $b$-axis. The cubane moieties are packed along the bc plane like pyramidal blocks in complementary sound absorbing panels.

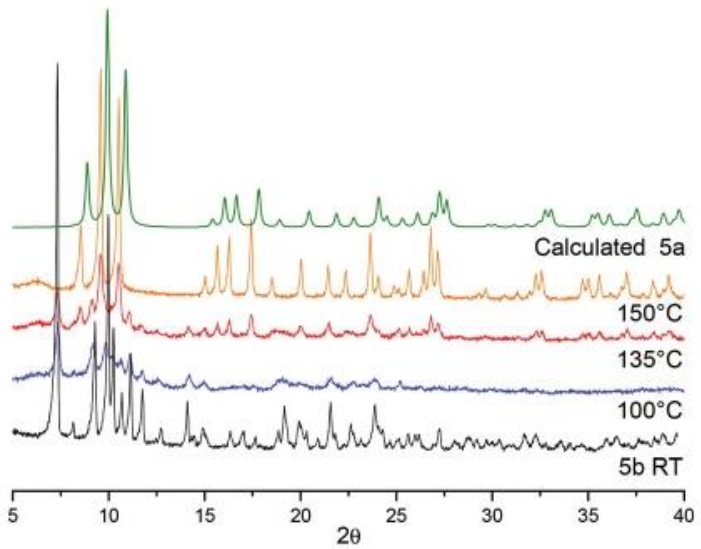

Fig. 6 Variable temperature XRPD analysis performed on $5 \mathrm{~b}, 100^{\circ} \mathrm{C}$ : loss of crystallinity due to the solvent release; $135^{\circ} \mathrm{C}$ (blue line): appear- ance of peaks of the $5 \mathrm{a}$ phase at $135^{\circ} \mathrm{C}$ (red line) and complete conver- sion to form $5 \mathrm{a}$ at 150 ${ }^{\circ} \mathrm{C}$ (orange line). The green line is the calculated pattern of $5 \mathrm{a}$ based on the structure solved at RT. The peak's shift of the orange pattern is ascribable to the cell expansion for the high temperature.

is observed due to the release of the disordered solvent mole- cules trapped into the channels (see ESI $\dagger$ ). At $135^{\circ} \mathrm{C}$, peaks of the $5 \mathrm{a}$ phase appear in the difractogram while the peak inten- sities of the $5 \mathrm{~b}$ phase decrease. A $5 \mathrm{~b}$ to $5 \mathrm{a}$ polymorphic conversion is complete at $150{ }^{\circ} \mathrm{C}$. After cooling down to ambient temperature no recovery of the $5 \mathrm{~b}$ phase occurs and the phase 5 a remains stable.

\section{Photophysical properties}

All complexes have been characterized by recording excitation and emission spectra and measuring luminescence quantum yields and lifetimes in the solid state. The photophysical data are reported in Table 2. Luminescence behaviour in solution

was not investigated since our aim was to evaluate the efect of the crystal structure on the photophysical properties. Moreover, all complexes are poorly soluble and their emission properties are expected to be largely depressed in solution as proved by the big drop in the luminescence quantum yield for 1 and 2 in solution (Table 2, in parentheses, taken from the literature $^{4}$ ) as a consequence of a big distortion of the excited state with respect to the ground state, which is also the reason

Table 2 Photophysical parameters for compounds $1-5 b$ as powders at room temperature. In brackets toluene solution data from the literature 4

\begin{tabular}{|c|c|c|c|c|c|c|c|}
\hline & $\lambda_{\text {exc }}{ }^{b}(n m)$ max & $\lambda_{\mathrm{em}}^{\mathrm{c}}(\mathrm{nm}) \max$ & Stokes shift $\left(\mathrm{cm}^{-1}\right)$ & $\Phi$ & $\tau^{d}(\mu s)$ & $\mathrm{k}_{\mathrm{r}}\left(10^{4} \mathrm{~s}^{-1}\right)$ & $\mathrm{k}_{\mathrm{nr}}\left(10^{4} \mathrm{~s}^{-1}\right)$ \\
\hline 1 & 360 & $570(690)$ & 10200 & $0.51(0.09)$ & $10.5(10.6)$ & $4.9(0.8)$ & $4.7(8.6)$ \\
\hline 2 & 370 & $570(680)$ & 9500 & $0.76(0.0002)$ & $12.3(0.11)$ & $6.2(0.2)$ & $2.0(910)$ \\
\hline 3 & 330 & 560 & 12400 & 0.44 & 10.6 & 4.2 & 5.3 \\
\hline 4 & 330 & 540 & 11800 & 0.50 & 14.2 & 3.5 & 3.5 \\
\hline $5 a$ & 350 & 550 & 10400 & 0.48 & 14.5 & 3.3 & 3.6 \\
\hline $5 b$ & 350 & 565 & 10900 & 0.30 & 10.3 & 2.9 & 6.8 \\
\hline $5 b$ & 340 & 565 & 11700 & 0.15 & 9.8 & 1.5 & 8.7 \\
\hline
\end{tabular}

${ }^{a}$ Data related to compound $5 \mathrm{~b}$ once heated at $80{ }^{\circ} \mathrm{C}$ and then cooled down to ambient temperature. ${ }^{\mathrm{b}}$ Excitation maxima, data recorded at maximum emission wavelength. ${ }^{\mathrm{c}}$ Emission maxima, excitation at $350 \mathrm{~nm}$. ${ }^{\mathrm{d}}$ Lifetimes, excitation at $331 \mathrm{~nm}$. The kinetic constants $\mathrm{k}_{\mathrm{r}}$ and $\mathrm{k}_{\mathrm{nr}}$ were calculated using the equations $\mathrm{k}_{\mathrm{r}}=\Phi / \tau$ and $\mathrm{k}_{\mathrm{rr}}=(1-\Phi)$. 


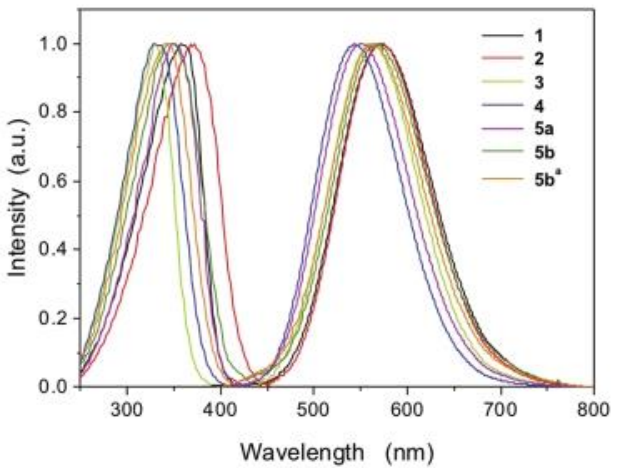

Fig. 7 Normalized excitation spectra $(250-450 \mathrm{~nm}$, excitation at the emission maximum) and emission spectra $\left(400-800 \mathrm{~nm}, \lambda_{\mathrm{ex}}=\right.$

$350 \mathrm{~nm}$ ). All measurements were done on powders at room temperature.

for the large red shift of the emission band. The fast radiation- less deactivation of the excited state in solution, represented by the high value of the decay constant $\mathrm{k}_{\mathrm{nr}}$ (Table 2), remarkably high for 2 , is associated with an efcient coupling of the ligand vibrations with the electronic transition. ${ }^{33}$

Apart from 1, having an unsaturated ligand whose $\pi^{*}$ orbitals are involved in the excitation conferring an ${ }^{1}$ XLCT character on the transition, the excitation spectra of all the other complexes are characterized by an envelope of bands extending below $400 \mathrm{~nm}$ which are associated with so-called "cluster centred" ( $\left.{ }^{1} \mathrm{CC}\right)$ electronic transitions which go from HOMOs, localized mainly on the iodide lone pairs, to LUMOs having $\mathrm{Cu}-\mathrm{Cu}$ bonding and $\mathrm{Cu}-\mathrm{I}$ antibonding character ${ }^{37,43}$ (Fig. 7). The emission bands have their maxima between $540 \mathrm{~nm}$ and $570 \mathrm{~nm}$ associated with radiative decay from cluster-centred triplet states $\left({ }^{3} \mathrm{CC}\right)$ characterized by lifetimes in the $10-15 \mu \mathrm{s}$ range and highly distorted with respect to the ground state geometry as shown by lack of vibrational structure and large Stokes shifts. ${ }^{37}$ This picture is consistent with cuprophilic interactions, which are compatible with $\mathrm{Cu}-\mathrm{Cu}$ distances inside the $\mathrm{Cu}_{4} \mathrm{I}_{4}$ clusters shorter than two times the van der Waals radius of $\mathrm{Cu}$ which has been recently evaluated as $1.92 \AA .{ }^{40,41}$ Even the rather long $\mathrm{Cu}-\mathrm{Cu}$ distances in $3(2.868 \AA$; $2.946 \AA$ ) do not prevent metal-metal interactions and ${ }^{3} \mathrm{CC}$ emission.

However, despite having similar origins, the luminescence transitions occur with diferent quantum yields for the diferent compounds.

Their values are in the 40-50\% range for most complexes, but a rather higher value for $2(76 \%)$ and a somewhat lower value for $5 \mathrm{~b}$ (30\%) have been measured. The quantum yield is dramatically increased compared to the data reported for 1 and 2 in solution; this behaviour agrees with an increase of the luminescence intensity upon stifening of the local environment. The quantum yield trend seems to correlate fairly well to the radiationless decay rate constant $\left(\mathrm{k}_{\mathrm{nr}}\right)$ which has the lowest value for 2. Only for this complex the crystalline structure highlights the presence of $\mathrm{N}-\mathrm{H} \cdots \mathrm{I}$ hydrogen bonds between adjacent clusters that assures rigidity to the $\mathrm{Cu}_{4} \mathrm{I}_{4}$ cubane core, preventing vibrations that promote non-radiative decay of the excited state. Thus, while 2 in solution has an extremely low quantum yield, it jumps to the highest values as a solid.

The cubane rigidity of this complex has some efect also on the radiative decay constant $\left(\mathrm{k}_{\mathrm{r}}\right)$, which is the highest one, and on the Stokes shift $\left(9500 \mathrm{~cm}^{-1}\right)$ which is lower than the other cluster values ranging from 10200 to $12400 \mathrm{~cm}^{-1}$. Both the efects can be correlated to a lower distortion of the excited state with respect to the ground state as a direct consequence of the $\mathrm{N}-\mathrm{H} \cdots \mathrm{I}$ hydrogen bond which enhances the cubane core stifness.

Accordingly, the more flexible crystal structure of $5 \mathrm{~b}$ afects both $\mathrm{k}_{\mathrm{r}}$ and $\mathrm{k}_{\mathrm{nr}}$, resulting in a lower luminescence quantum yield. An even lower value has been measured after heating at $80{ }^{\circ} \mathrm{C}$ and cooling down to room temperature the powder ( $5 \mathrm{~b}^{\mathrm{a}}$ in Table 2), as the desolvation process leads to loss of crystallinity.

The two isomorphous complexes $5 \mathrm{a}$ and 4 show similar quantum yields and kinetic constants.

\section{Thin films}

Direct deposition of the complex onto film was unsuccessful due to the degradation of the complex at high temperature and low pressure. Having stated that a solid-vapour reaction occurred when the copper iodide crystalline powder was exposed to the ligand vapours at room temperature, the same reaction was attempted with a $\mathrm{CuI}$ thin film. A thin copper iodide layer was deposited onto a polished glass slide by high- vacuum sublimation obtaining a polycrystalline, uniform, and smooth layer which showed the characteristic X-ray difraction (111) peak of the $\gamma$ phase. Then, the CuI film was exposed to the vapours of the ligand into a closed chamber until complete reaction, as suggested from the absence of any $\mathrm{CuI}$ peak in the XRPD analysis (see ESI $\dagger$ ). Our best results have been obtained by exposing a $35 \mathrm{~nm}$ thick CuI layer to the vapours of quinuclidine and of 3-quinuclidinol at room temperature. The X-ray difraction analysis directly performed in the Bragg-Brentano geometry on these films shows that they are both amorphous. The photoluminescence spectra of both films are in agreement with the emission spectra of the 4 and 5 a powders respectively. A sample obtained by reacting the $\mathrm{CuI}$ film with quinuclidine and showing a green luminescence when exposed to UV radiation $(\lambda=365 \mathrm{~nm})$ is reported in Fig. 8 .

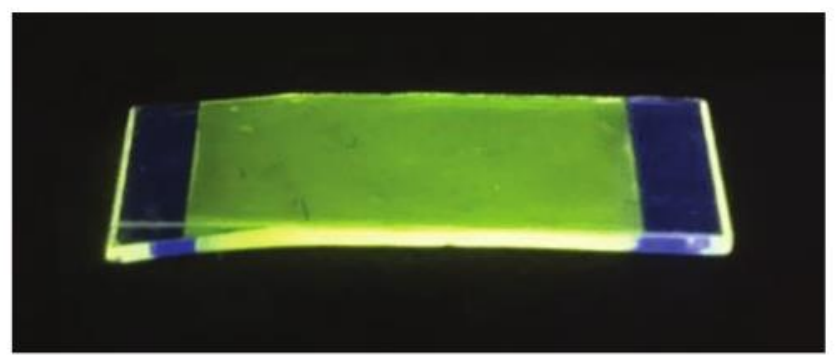

Fig. 8 Picture of Cul deposited onto a silica glass slide after exposition to vapour of quinuclidine under $365 \mathrm{~nm}$ UV lamp irradiation. 
When the $\mathrm{CuI}$ films were exposed to piperidine and $\mathrm{N}$ methylpiperidine vapours the reaction was too fast due to the higher vapour pressures of these ligands and the samples resulted as blotched and not uniformly emissive layers. More trials are in progress in order to improve the film uniformity by carefully controlling the solid-vapour reaction.

\section{Experimental section}

\section{General}

All glassware was dried in an oven set to a temperature of $80{ }^{\circ} \mathrm{C}$ for $24 \mathrm{~h}$ prior to use. All reagents were purchased from Sigma Aldrich and used without further purification.

\section{Photophysics}

All determinations made use of powder samples placed between two quartz slides and were done at room temperature. Excitation and emission spectra were obtained with a SPEX Fluorolog fluorometer; excitation spectra were monitored at the maximum emission wavelength and emission spectra were recorded exciting all samples at $350 \mathrm{~nm}$. Absolute photo- luminescence quantum yields were measured according to the method of deMello, ${ }^{4}$ by using an integrating sphere custo- mized to fit into the SPEX fluorometer sample compartment. The estimated error on the quantum yield is $10 \%$. Lumine- scence lifetimes were measured with an IBH 5000F time-corre- lated single-photon counting apparatus, by using a pulsed NanoLED excitation source at 331 $\mathrm{nm}$. Analysis of the lumine- scence decay profiles was accomplished with the Decay Analysis Software DAS6 provided by the manufacturer, with an esti- mated error on the lifetimes of 5\%. All decays were monoexpo-

nential. The kinetic constants $\mathrm{k}_{\mathrm{r}}$ and $\mathrm{k}_{\mathrm{nr}}$ were calculated using the equations $\mathrm{k}_{\mathrm{r}}=\Phi / \tau$ and $\mathrm{k}_{\mathrm{rr}}=(1-\Phi) / \tau$. ${ }^{45}$

\section{X-Ray powder difraction}

X-Ray powder difractograms were collected on a Panalytical X'Pert PRO automated difractometer with $\mathrm{CuK} \alpha$ radiation and an $X^{\prime}$ Celerator equipped with an Anton Paar TTK 450 low- temperature camera. The program Mercury ${ }^{46}$ was used for the calculation of X-ray powder patterns.

PXRD data of $5 \mathrm{a}$ were collected over the range $3-70^{\circ} 2 \theta$ ( $2 \mathrm{~kW}$; $\mathrm{Cu}-\mathrm{K} \alpha_{1}, 1.54056 \AA$ step size $0.0172 \theta$ ), using a variable count time scheme. ${ }^{47}$ The Bruker D8 Advance difractometer was equipped with a LynxEye detector. The data set was background subtracted and truncated to $50^{\circ} 2 \theta$ for Pawley fitting $\left(\chi^{2}=1.9\right)$. A scale-only Rietveld refinement against the original data was set in the range $4^{\circ}-65^{\circ} 2 \theta$ to give a good final fit,

$\mathrm{R}_{\mathrm{wp}}=2.89$.

\section{Crystal structure determination}

Crystal data for 3-4 and 5b were collected on an Oxford Xcalibur $\mathrm{S}$ with MoK $\alpha$ radiation, $\lambda=0.71073$, monochromator graphite and equipped with a liquid nitrogen Oxford-Cryostream device. Crystal data and details of measurements are summarized in Table 3. SHELX $97^{48}$ was used for the structure solution and refinement based on $\mathrm{F}^{2}$. Non-hydrogen atoms were refined anisotropically. The asymmetric unit of compound 3 consists of $1 / 8$ of the chemical formula $\left[\mathrm{Cu}_{4} \mathrm{I}_{4}\left(\mathrm{NC}_{6} \mathrm{H}_{13}\right)_{4}\right]$. The atoms $\mathrm{Cu} 1, \mathrm{I} 1, \mathrm{~N} 1, \mathrm{C} 3$ and $\mathrm{C} 4$ lay on the mirror plane. The asymmetric unit of compound 4 consists of two diferent cubane moieties. One moiety has the formula $\left[\mathrm{CuI}\left(\mathrm{NC}_{7} \mathrm{H}_{13}\right)\right]$ and all atoms are in general position while the second one has the formula $\left[\mathrm{CuI}\left(\mathrm{NC}_{7} \mathrm{H}_{13}\right)\right]_{0.3}$ and the atoms $\mathrm{Cu} 2, \mathrm{I} 4, \mathrm{~N} 2$ and C10 lay on the 3 -fold axes. The Mercury ${ }^{46}$ software package was used for the graphical representation of the resulting structures.

Synthesis of compound 1. CuI ( $1 \mathrm{mmol}, 0.190 \mathrm{~g})$ was dissolved in the minimum amount of a saturated aqueous solution of $\mathrm{KI}(\approx 2 \mathrm{~mL})$. While stirring, pyridine $(1.2 \mathrm{mmol}$, $0.01 \mathrm{~mL}$ ) was added. The product precipitated instantly as a whitish powder that gave yellow emission under UV/Vis radiation. The solid material was recovered by filtration on a Buchner funnel and washed with saturated KI aqueous solu- tion and bidistilled water. Once recovered, the powder has been dried in a desiccator with silica gel.

Synthesis of compound 2. CuI ( $1 \mathrm{mmol}, 0.190 \mathrm{~g})$ was dissolved in a minimum amount of a saturated aqueous solution

Table 3 Crystallographic data of compounds 1-5

\begin{tabular}{|c|c|c|c|c|c|c|}
\hline & $1^{49}$ & $2^{50}$ & 3 & 4 & $5 \mathrm{a}^{\mathrm{a}}$ & $5 b$ \\
\hline $\begin{array}{l}\text { Empirical formula } \\
\text { Formula weight }\end{array}$ & $\begin{array}{l}\mathrm{C}_{20} \mathrm{H}_{20} \mathrm{Cu}_{4} \mathrm{I}_{4} \mathrm{~N}_{4} \\
1098.4\end{array}$ & $\begin{array}{l}\mathrm{C}_{20} \mathrm{H}_{44} \mathrm{Cu}_{4} \mathrm{I}_{4} \mathrm{~N}_{4} \\
1102.39\end{array}$ & $\begin{array}{l}\mathrm{C}_{24} \mathrm{H}_{52} \mathrm{Cu}_{4} \mathrm{I}_{4} \mathrm{~N}_{4} \\
1158.46\end{array}$ & $\begin{array}{l}\mathrm{C}_{28} \mathrm{H}_{52} \mathrm{Cu}_{4} \mathrm{I}_{4} \mathrm{~N}_{4} \\
1206.50\end{array}$ & $\begin{array}{l}\mathrm{C}_{28} \mathrm{H}_{52} \mathrm{Cu}_{4} \mathrm{I}_{4} \mathrm{~N}_{4} \mathrm{O}_{4} \\
1270.50\end{array}$ & $\begin{array}{l}\mathrm{C}_{28} \mathrm{H}_{52} \mathrm{Cu}_{4} \mathrm{I}_{4} \mathrm{~N}_{4} \mathrm{O}_{4} \\
1270.50\end{array}$ \\
\hline Temperature & 293(2) K & 293(2) K & $293(2) \mathrm{K}$ & $293(2) \mathrm{K}$ & $293(2) \mathrm{K}$ & $293(2) \mathrm{K}$ \\
\hline Wavelength & 0.71073 & 0.71073 & 0.71073 & 0.71073 & 1.54056 & 0.71073 \\
\hline Crystal system & Orthorhombic & Tetragonal & Tetragonal & Cubic & Cubic & Monoclinic \\
\hline Space group & $\mathrm{P} 2{ }_{1} 2_{1} 2_{1}$ & $\mathrm{P} 4_{2} / \mathrm{n}$ & $\mathrm{I}^{4} \mathrm{~m}^{-}$ & $\mathrm{P} 43 \mathrm{n}^{-}$ & $\mathrm{P} 43 \mathrm{n}^{-}$ & $\mathrm{C} 2 / \mathrm{c}$ \\
\hline \multirow[t]{4}{*}{ Unit cell dimensions } & $\mathrm{a}=16.032(6)$ & $\mathrm{a}=14.589(1)$ & $\mathrm{a}=9.9963(7)$ & $a=19.7281(6)$ & $\mathrm{a}=19.9029(2)$ & $a=37.444(4)$ \\
\hline & $\mathrm{b}=15.510(2)$ & $\mathrm{b}=14.589(1)$ & $b=9.9963(7)$ & $b=19.7281(6)$ & $\mathrm{a}=19.9029(2)$ & $\mathrm{b}=12.2662(8)$ \\
\hline & $\mathrm{c}=11.756(3)$ & $\mathrm{c}=7.538(1)$ & $\mathrm{c}=18.114(2)$ & $c=19.7281(6)$ & $\mathrm{a}=19.9029(2)$ & $\mathrm{c}=20.000(2)$ \\
\hline & $\beta=90$ & $\beta=90$ & $\beta=90$ & $\beta=90$ & $\beta=90$ & $\beta=113.38(1)$ \\
\hline Volume & 2923.2 & 1604.7 & $1810.1(3)$ & $7678.1(4)$ & $7884.0(3)$ & $8431(1)$ \\
\hline $\mathrm{Z}$ & 2 & 2 & 2 & 8 & 8 & 8 \\
\hline CCDC number/ref. code & CUIPYR & CUIPIP & 975399 & 975300 & 975301 & 975302 \\
\hline
\end{tabular}

${ }^{\text {a }}$ Data obtained from Rietveld refinement on powder difraction pattern. 
of $\mathrm{KI}(\approx 2 \mathrm{~mL})$. While stirring, piperidine $(1.2 \mathrm{mmol}$,

$0.008 \mathrm{~mL}$ ) was added. The product precipitated instantly as a whitish powder that gave yellow emission under UV/Vis radiation. The solid material was recovered by filtration on a Buchner funnel and washed with saturated KI aqueous solu- tion and bidistilled water. Once recovered, the powder has been dried in a desiccator with silica gel.

Synthesis of compound 3. CuI ( $5 \mathrm{mmol}, 0.950 \mathrm{~g}$ ) were added as solid to $2 \mathrm{ml}$ of methyl-piperidine. After 3 days, during which time the suspension had been taken under stir- ring at room temperature in a closed flask, the product was fil- tered on a Buchner funnel and washed with an aqueous saturated solution of $\mathrm{KI}$ and bi-distilled cold water. Once recov- ered, the powder, which gave green emission under UV/Vis radiation, was dried in a desiccator with silica gel. The title compound was also obtained after 10 minutes of grinding, in an agate mortar, $0.190 \mathrm{~g}$ of $\mathrm{CuI}(1$ $\mathrm{mmol}$ ) with a few drops of methyl-piperidine. As the ligand is liquid and volatile at $\mathrm{rt}$, the title compound was obtained also via exposure of $\mathrm{CuI}$ to vapour of methyl-piperidine after 2 days. Single crystals were obtained by a three-layer crystallization: the lower layer was $\mathrm{CuI}$ dissolved in saturated aqueous solution of $\mathrm{KI}$; the middle layer was pure ethanol and the top layer was a solution of methyl-piperidine in acetone. Crystals appeared after 5-7 days and were chosen with the help of a UV lamp.

Synthesis of compound 4. CuI (0.095 g, $0.5 \mathrm{mmol})$ was dissolved in a minimum amount of a saturated aqueous solution of $\mathrm{KI}(\approx 2 \mathrm{~mL})$. While stiring, a solution of quinuclidine $(0.068 \mathrm{~g}, 0.6 \mathrm{mmol})$ in ethanol $(1 \mathrm{~mL})$ was added. The product precipitated instantly as a whitish powder with green emission under UV/Vis radiation. The solid material was recovered by filtration on a Buchner funnel and washed with saturated KI aqueous solution and bi-distilled water. Once recovered, the powder was dried in a desiccator with silica gel.

Single crystals were obtained by three-layer crystallization: the lower layer was $\mathrm{CuI}$ dissolved in saturated aqueous solu- tion of $\mathrm{KI}$; the middle layer was pure ethanol and the top layer was a solution of quinuclidine in $n$-hexane.

Synthesis of compound 5a. Racemic 3-quinuclidinol $(0.127 \mathrm{~g}, 1.2 \mathrm{mmol})$ was dissolved in methanol $(1 \mathrm{~mL})$ at $80{ }^{\circ} \mathrm{C}$ and was added, under stirring, to a saturated $\mathrm{KI}$ aqueous solu- tion of $\mathrm{CuI}(0.190 \mathrm{~g}, 1 \mathrm{mmol})$ at $80^{\circ} \mathrm{C}$. The product was preci- pitated as a fine white powder, with green emission under UV/ Vis radiation; the solid material was recovered by filtration with a Buchner funnel and washed with saturated KI aqueous solution and bi-distilled water. Once recovered, the powder was dried in a desiccator with silica gel.

Synthesis of compound 5b. CuI ( $1 \mathrm{mmol}, 0.190 \mathrm{~g})$ were added as solid into a flask filled with a solution of racemic 3-quinuclidinol (1 mmol, $0.127 \mathrm{~g}$ ) in methanol (4 mL). 24 hours later the product was filtered on a Buchner funnel and washed with an aqueous saturated solution of KI and bi- distilled cold water. Once recovered, the powder was dried in a desiccator with silica gel. The title compound was also obtained after several hours of grinding in a ball milling a $1: 1$ physical mixture of the reagents with a catalytic amount of ethanol. Single crystals were obtained by three-layer crystallization: the lower layer was $\mathrm{CuI}$ dissolved in saturated aqueous solution of KI; the middle layer was pure ethanol and the top layer was a solution of 3-quinuclidinol in water. Crystals appeared after 5-7 days and were chosen with the help of a UV lamp.

\section{Conclusions}

Two known (1 and 2) and four new (3, 4, 5a and 5b) tetrakis- $\left(\left(\mu_{3}-\right.\right.$ iodo)-ligand-copper(I)) cubane complexes have been synthesized as crystalline powders and their photophysical properties have been measured. The crystal structures of $3,4,5 b$ have been determined by single crystal X-ray difraction while $5 \mathrm{a}$ was solved from the powder data.

All complexes show a cubane $\mathrm{Cu}_{4} \mathrm{I}_{4}$ core and are luminescent due to radiative decay of a cluster centred ${ }^{3} \mathrm{CC}$ emitting state. Quantum yields are in the range of $40-50 \%$ for all complexes apart from a slightly lower $30 \%$ for $5 \mathrm{~b}$ and a signifi- cantly higher value of $76 \%$ for 2 which, to the best of the authors' knowledge, has never been demonstrated previously for cubane complexes. No significant interactions between the constituting moieties are observed in the crystal structures of the complexes except for compound 2 where the clusters are held together by hydrogen bonds in pillars. It results that each cluster is involved in eight hydrogen bonds, and clusters are aligned along the c-axis to build a stif columnar structure. We think that these interactions make the cluster extremely rigid and allow to get a very high luminescence quantum yield. On the other hand, the less rigid structure of $5 b$ results in the lowest quantum yield (30\%). Desolvation of $5 \mathrm{~b}$ leads to loss of crystallinity which results in an even more reduced quantum yield $(15 \%)$.

Some preliminary attempts to obtain thin films of the pure complexes have been made by using solid-vapour reactions and some uniformly luminescent samples have been obtained. These results may be a first indication of the possibility of application of these complexes as emissive layers in electroluminescent devices, as they do not sufer from concentration quenching and have emissive triplet excited states which are compliant with the "triplet harvesting" frame for high efciency OLEDs.

\section{Acknowledgements}

We thank MIUR, University of Bologna and CNR for financial support of this research. PPM thanks the University of Bologna for a $\mathrm{PhD}$ grant and the Marco Polo fellowship for supporting his visiting period at Reading University.

\section{Notes and references}

1 F. G. Mann, D. Purdie and A. F. Wells, J. Chem. Soc., 1936, 447-460.

2 G. Tartarini, Gazz. Chim. Ital., 1933, 63, 597-600. 
3 N. Armaroli, G. Accorsi, F. Cardinali and A. Listorti, in Photochemistry and Photophysics of Coordination Compounds I, ed. V. Balzani and S. Campagna, Springer-Verlag, Berlin, 2007, vol. 280, pp. 69-115.

4 K. R. Kyle, C. K. Ryu, P. C. Ford and J. A. DiBenedetto, J. Am. Chem. Soc., 1991, 113, 2954-2965.

5 P. C. Ford and A. Vogler, Acc. Chem. Res., 1993, 26, 220-226. 6

P. C. Ford, Coord. Chem. Rev., 1994, 132, 129-140.

7 H. D. Hardt and A. Pierre, Inorg. Chim. Acta, 1977, 25, L59L60.

8 H. D. Hardt, H. Gechnizdjani and A. Pierre, Naturwissenschaften, 1972, 59, 363.

9 H. D. De Ahna and H. D. Hardt, Z. Anorg. Allg. Chem., 1972, 387, 61-71.

10 P. C. Ford, E. Cariati and J. Bourassa, Chem. Rev., 1999, 99, 3625-3648.

11 H. D. Hardt and A. Pierre, Naturwissenschaften, 1975, 62, 298.

12 P. P. Mazzeo, L. Maini, D. Braga, G. Valenti, F. Paolucci, M. Marcaccio, A. Barbieri and B. Ventura, Eur. J. Inorg. Chem., 2013, 2013, 4459-4465.

13 C. H. Arnby, S. Jagner and I. Dance, CrystEngComm, 2004, 6, 257-275.

14 R. Peng, S. R. Deng, M. Li, D. Li and Z. Y. Li, CrystEngComm, 2008, 10, 590-597.

15 S. Q. Bai, J. Y. Kwang, L. L. Koh, D. J. Young and T. S. A. Hor, Dalton Trans., 2010, 39, 2631-2636.

16 Z. Liu, M. F. Qayyum, C. Wu, M. T. Whited, P. I. Djurovich, K. O. Hodgson, B. Hedman, E. I. Solomon and M. E. Thompson, J. Am. Chem. Soc., 2011, 133, 3700-3703.

17 Z. Liu, P. I. Djurovich, M. T. Whited and M. E. Thompson, Inorg. Chem., 2011, 51, 230-236.

18 S. Perruchas, X. F. L. Gof, S. Maron, I. Maurin, F. o. Guillen, A. Garcia, T. Gacoin and J.-P. Boilot, J. Am. Chem. Soc., 2010, 132, 10967-10969.

19 D. Volz, D. M. Zink, T. Bocksrocker, J. Friedrichs, M. Nieger, T. Baumann, U. Lemmer and S. Brase, Chem. Mater., 2013, 25, 3414-3426.

20 N. Thejo Kalyani and S. J. Dhoble, Renew. Sust. Energ. Rev., 2012, 16, 2696-2723.

21 Y.-L. Chang, Y. Song, Z. Wang, M. G. Helander, J. Qiu, L. Chai, Z. Liu, G. D. Scholes and Z. Lu, Adv. Funct. Mater., 2013, 23, 705-712.

22 M. C. Gather, A. Köhnen and K. Meerholz, Adv. Mater., 2011, 23, 233-248.

23 M. Dong and L. Zhong, IEEE Trans. Mobile Comput., 2012, 11, 1587-1599.

24 J. C. Jeong, H. S. Kim and J. G. Jang, Mol. Cryst. Liq. Cryst, 2010, 530, 259-265.

25 P. Brulatti, V. Fattori, S. Muzzioli, S. Stagni, P. P. Mazzeo, D. Braga, L. Maini, S. Milita and M. Cocchi, J. Mater. Chem. C, 2013, 1, 1823-1831.

26 Y.-L. Tung, P.-C. Wu, C.-S. Liu, Y. Chi, J.-K. Yu, Y.-H. Hu, P.-T. Chou, S.-M. Peng, G.-H. Lee, Y. Tao, A. J. Carty,
C.-F. Shu and F.-I. Wu, Organometallics, 2004, 23, 37453748.

27 D. Volz, M. Nieger, J. Friedrichs, T. Baumann and S. Brase, Langmuir, 2013, 29, 3034-3044.

28 D. M. Zink, M. Bachle, T. Baumann, M. Nieger, M. Kuhn, C. Wang, W. Klopper, U. Monkowius, T. Hofbeck, H. Yersin and S. Brase, Inorg. Chem., 2012, 52, 2292-2305.

29 J. P. Safko, J. E. Kuperstock, S. M. McCullough, A. M. Noviello, X. Li, J. P. Killarney, C. Murphy, H. H. Patterson, C. A. Bayse and R. D. Pike, Dalton Trans., 2012, 41, 11663-11674.

30 D. Braga, F. Grepioni, L. Maini, P. P. Mazzeo and

B. Ventura, New J. Chem., 2011, 35, 339-344.

31 D. Braga, L. Maini, P. P. Mazzeo and B. Ventura, Chem. - Eur. J., 2010, 16, 1553-1559.

32 L. Maini, D. Braga, P. P. Mazzeo and B. Ventura, Dalton Trans., 2012, 41, 531-539.

33 M. Vitale and P. C. Ford, Coord. Chem. Rev., 2001, 219-221, 3-16.

34 M. Vitale, W. E. Palke and P. C. Ford, J. Phys. Chem., 1992, 96, 8329-8336.

35 C. K. Ryu, M. Vitale and P. C. Ford, Inorg. Chem., 1993, 32, 869-874.

36 C. K. Ryu, K. R. Kyle and P. C. Ford, Inorg. Chem., 1991, 30, 3982-3986.

37 F. De Angelis, S. Fantacci, A. Sgamellotti, E. Cariati, R. Ugo and P. C. Ford, Inorg. Chem., 2006, 45, 1057610584.

38 D. Tran, J. L. Bourassa and P. C. Ford, Inorg. Chem., 1997, 36, 439-442.

39 A. Dossing, C. K. Ryu, S. Kudo and P. C. Ford, J. Am. Chem. Soc., 1993, 115, 5132-5137.

40 S. S. Batsanov, Inorg. Mater., 2001, 37, 871-885.

41 S. Nag, K. Banerjee and D. Datta, New J. Chem., 2007, 31, 832-834.

42 L. Brammer, E. A. Bruton and P. Sherwood, Cryst. Growth Des., 2001, 1, 277-290.

43 A. Vega and J.-Y. Saillard, Inorg. Chem., 2004, 43, 40124018.

44 A. Barbieri and G. Accorsi, EPA Newsletters, December 2006, 26-35.

45 J. R. LakowiczJ, Principle of fluorescence Spectroscopy, Springer, New York, 3rd edn, 2006.

46 C. F. Macrae, I. J. Bruno, J. A. Chisholm, P. R. Edgington, P. McCabe, E. Pidcock, L. Rodriguez-Monge, R. Taylor, J. van de Streek and P. A. Wood, J. Appl. Crystallogr., 2008, 41, 466-470.

47 K. Shankland, W. I. F. David and D. S. Sivia, J. Mater. Chem., 1997, 7, 569-572.

48 G. M. Sheldrick, SHELXL97, University of Göttingen, Germany, 1997.

49 C. L. Raston and A. H. White, J. Chem. Soc., Dalton Trans., 1976, 2153-2156.

50 V. Schramm, Inorg. Chem., 1978, 17, 714-718. 